\title{
Maternal breast cancer risk in relation to birthweight and gestation of her offspring
}

\author{
Anthony J. Swerdlow ${ }^{1,2^{*}}$ D, Lauren B. Wright ${ }^{1}$, Minouk J. Schoemaker ${ }^{1}$ and Michael E. Jones ${ }^{1}$
}

\begin{abstract}
Background: Parity and age at first pregnancy are well-established risk factors for breast cancer, but the effects of other characteristics of pregnancies are uncertain and the literature is inconsistent.

Methods: In a cohort of 83,451 parous women from the general population of the UK, which collected detailed information on each pregnancy and a wide range of potential confounders, we investigated the associations of length of gestation and birthweight of offspring in a woman's pregnancies with her breast cancer risk, adjusting for a full range of non-reproductive as well as reproductive risk factors unlike in previous large studies.

Results: Gestation of the first-born offspring was significantly inversely related to the risk of pre-menopausal breast cancer ( $p$ trend $=0.03$; hazard ratio (HR) for 26-31 compared with 40-41 weeks, the baseline group, $=2.38,95 \%$ confidence interval (Cl) 1.26-4.49), and was borderline significantly related to risk of breast cancer overall ( $p$ trend $=0.05$ ). Risk was significantly raised in mothers of high birthweight first-born ( $H R$ for breast cancer overall $=1.53,95 \% \mathrm{Cl} 1.06-2.21$ for $\geq 4500 \mathrm{~g}$ compared with 3000-3499 g, the baseline group). For gestation and birthweight of most recent birth, there were no clear effects. Analyses without adjustment for confounders (other than age) gave similar results.

Conclusions: Our data add to evidence that short gestation pregnancies may increase the risk of breast cancer, at least pre-menopausally, perhaps by hormonal stimulation and breast proliferation early in pregnancy without the opportunity for the differentiation that occurs in late pregnancy. High birthweight first pregnancies may increase breast cancer risk, possibly through the association of birthweight with oestrogen and insulin-like growth factor 1 levels.
\end{abstract}

Keywords: Breast cancer, Risk, Birthweight, Gestation, Offspring

\section{Background}

It has long been known that a woman's risk of breast cancer relates to the number of pregnancies she has had and the age at which she first gave birth $[1,2]$. Serum levels of oestrogens and several other hormones are far higher during pregnancy than at other points in life [35], and there are major histological changes in the breast during pregnancy [6] giving plausible mechanisms for such effects. One might therefore expect that characteristics of the pregnancies, such as the length of gestation and the birthweight of the offspring, that are associated with maternal hormone levels [7-14] might also affect breast cancer risk. Investigations of this have been far more limited, however, than for age at first birth and

\footnotetext{
* Correspondence: Anthony.swerdlow@icr.ac.uk

${ }^{1}$ Division of Genetics and Epidemiology, The Institute of Cancer Research, Sir Richard Doll Building, London SM2 5NG, UK

${ }^{2}$ Division of Breast Cancer Research, The Institute of Cancer Research, London SW3 6JB, UK
}

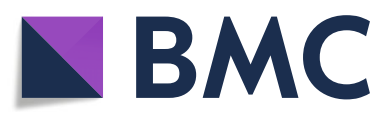

(c) The Author(s). 2018 Open Access This article is distributed under the terms of the Creative Commons Attribution 4.0 International License (http://creativecommons.org/licenses/by/4.0/), which permits unrestricted use, distribution, and

reproduction in any medium, provided you give appropriate credit to the original author(s) and the source, provide a link to the Creative Commons license, and indicate if changes were made. The Creative Commons Public Domain Dedication waiver (http://creativecommons.org/publicdomain/zero/1.0/) applies to the data made available in this article, unless otherwise stated. parity, and results have been inconsistent. The large studies [15-24] have all been based on record linkage, and consequently have generally not been able to adjust for non-reproductive confounders, which might be important since several factors such as maternal height, birthweight, smoking, and alcohol consumption, that are associated with the offspring's birthweight and gestation [25-31], are also known or likely risk factors for breast cancer. Also, with one exception for hormone receptor type [23], these studies have not analysed risks in subdivisions of breast cancer that may have different aetiological characteristics-by menopausal status at the time of breast cancer incidence, by in-situ versus invasive status, and by hormone receptor subtype.

We therefore analysed the relation of offspring's birthweight and gestation to maternal breast cancer risk in a large UK cohort in which information on birthweight and other characteristics was collected separately for each 
pregnancy, and in which extensive information was collected on potential confounders and virtually complete information on breast cancer characteristics.

\section{Methods}

The Generations Study is a cohort study of $>113,000$ women from the general population of the UK recruited since 2003 at age 16 years and older [32]. At recruitment, the participants completed a detailed questionnaire about potential risk factors for breast cancer and donated a blood sample. The recruitment questionnaire asked about several variables, including birthweight and gestation, the variables addressed in this paper, for each of the subject's pregnancies, and also about all known and likely causes of breast cancer. The pregnancy information was updated at the second follow-up questionnaire, 6 years after recruitment, for any subsequent pregnancies.

Follow-up of the cohort is primarily by questionnaires, which have been completed at approximately 3-year intervals with high completeness: by $99 \%$ of non-deceased participants at the first follow-up, $97 \%$ at the second, and $95.5 \%$ at the third. Follow-up for cancer incidence and mortality of the small proportion who did not respond to questionnaires was by 'flagging' at the National Health Service Central Registers (NHSCRs), virtually complete population registers of England and Wales, and of Scotland, in which deaths and cancer registrations are 'flagged' and are then reported to authorised medical researchers. The study was approved by the South East Multi-centre Ethics Committee.

Cancers occurring in the cohort during follow-up were identified from follow-up questionnaire responses and from spontaneous reports to the investigators, as well as by flagging at the NHSCRs of participants who did not reply to questionnaires. Cancer diagnoses were confirmed by cancer registration data via the NHSCRs, pathology reports, and correspondence with physicians. To facilitate comparison with the great majority of the previous literature [15-19, 22-24, 33, 34], we have presented analyses for invasive breast cancer in the main tables, but also have analysed risks for in-situ breast cancer (in Additional file 1:Table S1) for which there appear to be no previous data.

The current analytic cohort consisted of all women who were recruited into the Generations Study from its launch (June 2003) to December 2013, without prior invasive breast cancer or mastectomy. The cut-off date of December 2013 was used because, at the time of analysis, at least second-round follow-up was complete for these recruits (timing of follow-up rounds is personalised depending on their date of recruitment).

We initially analysed first-birth characteristics in relation to subsequent risk of breast cancer. For this, study subjects entered analytic risk at the date they were recruited to the cohort if already parous, or at the date of first delivery at $\geq 26$ weeks gestation if recruited nulliparous, and left at the earliest of first invasive breast cancer diagnosis, death, most recent follow-up questionnaire, or loss to follow-up. Women whose first delivery was of twins or multiple babies were excluded from these analyses since having borne twins has been found to be associated with a reduced risk of breast cancer [35] and twins tend to be delivered early and have reduced birthweight. Similar analyses were conducted for risks in relation to most recent ('last') $\geq 26$ weeks delivery on a time-dependent basis (i.e. re-setting duration since last birth to zero after each birth).

We also conducted separate analyses of follow-up before and after 15 years since delivery, since there is strong evidence that pregnancy has two opposite effects on breast cancer risk: an increase in the short-term, up to about 15 years, followed by a long-term protective effect [36].

We estimated hazard ratios (HRs) and 95\% confidence intervals (CIs) for risk of breast cancer in relation to gestation and birthweight of offspring, by left-truncated right-censored Cox proportional hazards regression [37] with attained age as the implicit time scale. Analyses were adjusted for multiple reproductive and non-reproductive potential confounders, as listed in the footnotes to the Tables. Time since entry to cohort, smoking start age, alcohol consumption, current oral contraceptive use, parity, menopausal status, and menopausal hormone therapy use, were treated as time-varying exposures. All $p$ values are two-sided. Analyses were conducted using Stata, version 14.2 [38].

Trends were analysed in the Cox regression model by fitting continuous values of the risk factor, and subjects with missing data for the risk factor were included in the statistical model as a separate categorical term by fitting appropriate interaction terms. Tests for trend were determined by assessing whether the slope parameter in the statistical model differed from zero using the Wald test [39].

Tests for interaction in trends for analyses by menopausal status (to assess effect modification) were assessed by fitting additional interaction terms for menopausal status and the continuous risk factor and testing if the difference in trends differed from zero using the Wald test. For analyses by subtype of breast cancer defined by receptor status (to assess effect heterogeneity) we used a data augmentation method [40] to test if the difference in trends differed from zero using the Wald test.

Since pre-eclampsia has been found to be associated with reduced risks of subsequent breast cancer [41] and often with early delivery and reduced birthweight, and diabetes is associated with breast cancer risk (although only post-menopausally) $[42,43]$ and raised birthweight of offspring [44], we conducted sensitivity analyses excluding 
women with diabetes and women with pre-eclampsia in the birth(s) under analysis.

\section{Results}

There are 107,480 participants in the Generations Study cohort recruited in 2003-2013 who did not have prior breast cancer or mastectomy at recruitment, of whom 85,069 had had any pregnancies by the time of their second follow-up questionnaire and formed the potential analytic cohort.

For analyses of first births, we excluded 1214 women whose first birth was twins or a higher order, and 404 with inadequate or erroneous data, leaving 83,451 for analysis. For analyses of other births there were similar exclusions. The characteristics at recruitment of the analytic cohort are shown in Table 1 . Women entered the cohort at a wide range of ages, largely under 65 years, and half had had two pregnancies before recruitment.

During follow-up after first birth, 980 subjects had died, 1767 had developed invasive breast cancer, 80,043 had survived to their end date without breast cancer, and 661 were lost to follow-up (e.g. because of emigration) before their end date. We obtained pathological

Table 1 Characteristics of analytic cohort

\begin{tabular}{|c|c|c|}
\hline Characteristic & $n$ & $\%$ \\
\hline \multicolumn{3}{|l|}{ Year of birth } \\
\hline 1908-39 & 5899 & 7.1 \\
\hline 1940-49 & 20,519 & 24.6 \\
\hline $1950-59$ & 21,619 & 25.9 \\
\hline 1960-69 & 19,350 & 23.2 \\
\hline 1970-96 & 16,064 & 19.2 \\
\hline \multicolumn{3}{|c|}{ Year of start of analytic follow-up ${ }^{a}$} \\
\hline $2003-5$ & 24,015 & 28.8 \\
\hline $2006-7$ & 39,062 & 46.8 \\
\hline 2008-13 & 20,374 & 24.4 \\
\hline \multicolumn{3}{|c|}{ Age at start of analytic follow-up (years) ${ }^{\mathrm{a}}$} \\
\hline $16-34$ & 11,950 & 14.3 \\
\hline $35-44$ & 19,741 & 23.7 \\
\hline $45-54$ & 21,016 & 25.2 \\
\hline $55-64$ & 22,461 & 26.9 \\
\hline$\geq 65$ & 8283 & 9.9 \\
\hline \multicolumn{3}{|c|}{ Parity at start of analytic follow-up ${ }^{a}$} \\
\hline 1 & 19,917 & 23.9 \\
\hline 2 & 42,862 & 51.4 \\
\hline 3 & 16,229 & 19.5 \\
\hline$\geq 4$ & 4443 & 5.3 \\
\hline Total & 83,451 & 100.0 \\
\hline
\end{tabular}

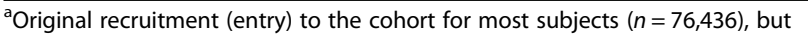
date of first delivery at $\geq 26$ weeks gestation for those who were nulliparous at original cohort entry $(n=7015)$ confirmation of diagnoses for all of the reported breast cancers except 12, which were based on self-report plus a report of appropriate treatment.

Table 2 shows the risks of breast cancer in the cohort in relation to birthweight and gestation of the offspring of the woman's first pregnancy, overall and by menopausal status at breast cancer. Compared with mothers of offspring with birthweights 3000-3499 g, the most numerous group, risk was significantly raised $(\mathrm{HR}=1.53$, 95\% CI 1.06-2.21) in those with the heaviest offspring $(\geq 4500 \mathrm{~g})$, with non-significant tendencies in the same direction for pre-menopausal and post-menopausal breast cancer separately. There was also a tendency to raised risks for mothers of the lowest birthweight children, which was significant for pre-menopausal but not for overall breast cancer. For gestation, there was a borderline significant inverse trend in breast cancer risk overall $(p=0.05)$, which was significant pre-menopausally $(p=0.03)$, with the greatest risk for those who had given birth at 26-32 weeks (HR $=2.38,95 \%$ CI 1.26-4.49). In sensitivity analyses excluding women with diabetes and those with pre-eclampsia in the first pregnancy, results were similar (data not shown). Adjustment of the gestation analyses for birthweight did not substantially alter the results. In separate analyses for in-situ breast cancers (Additional file 1: Table S1) there was no evidence of raised risk for either women with high birthweight first-born or short gestation births, although this was based on much smaller numbers than for invasive tumours.

The oestrogen receptor (ER) status of the tumour was known for $99.3 \%$ of invasive breast cancers. The raised risk in mothers of high birthweight first-borns appeared present for both ER-positive and ER-negative tumours, although it was not significant in either, whereas the raised risk for mothers of low gestation first-borns appeared evident only for ER-positive tumours, although again this was not significant (Table 3).

When we divided follow-up time into $<15$ years and $\geq$ 15 years since first delivery (Table 4), the effect of high birthweight was significant for the latter period, whereas the trend with gestation appeared steeper in the first 15 years of follow-up, although not significantly based on relatively small numbers.

When analysed separately for first deliveries under the age of 30 years and older than this, the effects of birthweight and gestation were in the same direction for each, although not significantly based on smaller numbers (Additional file 1: Table S2).

Analyses of risk in relation to most recent pregnancy rather than first pregnancy gave less marked results (Table 5). Risk was non-significantly raised for mothers of high birthweight offspring and appeared to be unrelated to gestation of offspring. Repetition of the above analyses without adjustment for confounders (other than 
Table 2 Invasive breast cancer risk by birthweight and gestation of first-born singleton offspring by menopausal status ${ }^{\mathrm{a}}$

\begin{tabular}{|c|c|c|c|c|c|c|c|c|c|}
\hline \multirow[t]{2}{*}{ Risk factor } & \multicolumn{3}{|c|}{ Pre-menopausal $^{a}$} & \multicolumn{3}{|c|}{ Post-menopausal $^{a}$} & \multicolumn{3}{|c|}{ Breast cancer overall } \\
\hline & No. of cases & $H R^{b}$ & $95 \% \mathrm{Cl}$ & No. of cases & $H R^{b}$ & $95 \% \mathrm{Cl}$ & No. of cases & $H R^{b}$ & $95 \% \mathrm{Cl}$ \\
\hline \multicolumn{10}{|l|}{ Birthweight (g) } \\
\hline$<2000$ & 8 & 2.05 & $1.01-4.17^{c}$ & 10 & 0.91 & $0.48-1.70$ & 18 & 1.21 & $0.76-1.94$ \\
\hline $2000-2499$ & 11 & 0.78 & $0.42-1.43$ & 56 & 1.10 & $0.83-1.45$ & 67 & 1.03 & $0.80-1.33$ \\
\hline 2500-2999 & 62 & 1.06 & $0.79-1.42$ & 231 & 1.13 & $0.97-1.32$ & 293 & 1.12 & $0.97-1.28$ \\
\hline 3000-3499 & 162 & 1.00 & & 514 & 1.00 & & 676 & 1.00 & \\
\hline 3500-3999 & 141 & 1.10 & $0.88-1.38$ & 360 & 0.98 & $0.85-1.12$ & 501 & 1.01 & $0.90-1.13$ \\
\hline 4000-4499 & 35 & 1.01 & $0.70-1.46$ & 86 & 1.01 & $0.80-1.27$ & 121 & 1.01 & $0.83-1.22$ \\
\hline$\geq 4500$ & 10 & 1.73 & $0.91-3.28$ & 20 & 1.46 & $0.93-2.28$ & 30 & 1.53 & $1.06-2.21^{\mathrm{c}}$ \\
\hline Not known & 20 & 1.76 & $1.11-2.81^{c}$ & 41 & 0.98 & $0.71-1.35$ & 61 & 1.14 & $0.88-1.49$ \\
\hline$p$ trend $^{d}$ & & 0.55 & & & 0.50 & & & 0.86 & \\
\hline \multicolumn{10}{|c|}{$p$ interaction $($ trend $)=0.39$} \\
\hline \multicolumn{10}{|c|}{ Gestation (weeks) } \\
\hline $26-31$ & 10 & 2.38 & $1.26-4.49^{e}$ & 12 & 0.95 & $0.53-1.68$ & 22 & 1.30 & $0.85-1.99$ \\
\hline $32-36$ & 33 & 1.23 & $0.85-1.78$ & 117 & 1.09 & $0.89-1.33$ & 150 & 1.10 & $0.92-1.32$ \\
\hline $37-39$ & 116 & 0.92 & $0.73-1.15$ & 355 & 1.14 & $0.99-1.30$ & 471 & 1.07 & $0.95-1.21$ \\
\hline $40-41$ & 200 & 1.00 & & 481 & 1.00 & & 681 & 1.00 & \\
\hline$\geq 42$ & 70 & 0.93 & $0.71-1.22$ & 175 & 1.06 & $0.89-1.26$ & 245 & 1.02 & $0.88-1.18$ \\
\hline Not known & 20 & 0.83 & $0.53-1.32$ & 178 & 1.09 & $0.91-1.30$ & 198 & 1.04 & $0.88-1.22$ \\
\hline$p$ trend $^{d}$ & & 0.03 & & & 0.28 & & & 0.05 & \\
\hline$p$ interaction (tr & $=0.21$ & & & & & & & & \\
\hline
\end{tabular}

$H R$ hazard ratio, $\mathrm{Cl}$ confidence interval

${ }^{\text {a } M e n o p a u s a l}$ status at breast cancer incidence

bAdjusted for: attained age (Cox regression time scale); time since recruitment to cohort (0, 1-2, 3+ years); birth cohort (1908-1939, 1940-1949, 1950-1959, 1960-1969, 1970-1996); benign breast disease (yes, no); family history of breast cancer in first-degree relatives (yes, no); socio-economic score (ACORN score as trend, missing); own birthweight (trend, missing); age at menarche (trend, missing); parity (trend); age at first pregnancy (trend); cumulative duration of breast feeding (none, duration trend when reported); current oral contraceptive use before menopause (yes, no); height at age 20 (trend, missing); alcohol consumption (never regular, trend current drinker 1 to $<60 \mathrm{~g} /$ day, current drinker $60+\mathrm{g} /$ day, past drinker, drinker with unknown details); age started smoking (never, $<17,17-19,20+$, missing); physical activity (log(metabolic equivalent) trend, missing); pre-menopausal body mass index at age 20 years (trend, missing); menopausal status (pre- or post-menopausal), and for those post-menopausal, post-menopausal body mass index (trend, missing), menopausal hormone therapy use (never used, ex-user, current oestrogen-only user, current oestrogen plus progestogen user, current user of other types, missing), and age at menopause (trend, missing)

${ }^{c} p<0.05$

${ }^{d}$ Excluding not known category

${ }^{\mathrm{e}} p<0.01$

age) (Additional file 1: Tables S3-S6) gave very similar results-HRs for high birthweight tended to be slightly more elevated, and those for low birthweight slightly less elevated, than in the adjusted analyses. Repetition of the adjusted gestation analyses with and without adjustment for breast feeding (since breast feeding is associated with breast tissue differentiation) showed no significant interaction $(p=0.31)$.

\section{Discussion}

Mammary cells in animals proliferate in the first and second trimesters of pregnancy and differentiate in the third trimester [45], and the same is seen in the breast in humans $[46,47]$. Thus, one might expect that pregnancies that continue to term or beyond might increase the extent of differentiation and hence protect (in the long term) against breast cancer. Conversely, a pregnancy that ends at an early stage might lead to increased risk through cell proliferation and high sex hormone levels promoting growth of partially transformed cells [36], without subsequent differentiation. Our results were in accord with this, with the risk greatest for early gestation births and decreasing with longer gestation, significantly for pre-menopausal tumours and borderline significantly for breast cancer overall. Previous analyses of the relation of long-term risk to gestation of the first birth have been based on record linkage; the results have not been entirely consistent and also give some uncertainty in comparison because of varying categorisations of gestation. Most have found results in the same direction as ours, significantly $[15,17,18,22]$ or not significantly [21], but some have not found such a relation [19, 20,34]. Studies have generally found induced abortion unrelated to risk of subsequent breast cancer [48], but abortion is generally at far shorter gestations than those analysed in our data; we 
Table 3 Invasive breast cancer risk by birthweight and gestation of first-born singleton offspring by oestrogen-receptor status ${ }^{\text {a }}$

\begin{tabular}{|c|c|c|c|c|c|c|}
\hline & \multicolumn{6}{|c|}{ Oestrogen receptor status ${ }^{a}$} \\
\hline & \multicolumn{3}{|l|}{ Positive } & \multicolumn{3}{|l|}{ Negative } \\
\hline & No. of cases & $H R^{b}$ & $95 \% \mathrm{Cl}$ & No. of cases & $H R^{b}$ & $95 \% \mathrm{Cl}$ \\
\hline \multicolumn{7}{|l|}{ Birthweight (g) } \\
\hline$<2000$ & 16 & 1.32 & $0.80-2.17$ & 2 & 0.86 & $0.21-3.49$ \\
\hline $2000-2499$ & 58 & 1.09 & $0.83-1.42$ & 7 & 0.70 & $0.33-1.51$ \\
\hline 2500-2999 & 228 & 1.06 & $0.90-1.23$ & 57 & 1.42 & $1.03-1.96^{c}$ \\
\hline $3000-3499$ & 555 & 1.00 & & 104 & 1.00 & \\
\hline 3500-3999 & 404 & 0.99 & $0.87-1.13$ & 81 & 1.05 & $0.79-1.41$ \\
\hline $4000-4499$ & 95 & 0.97 & $0.78-1.21$ & 20 & 1.07 & $0.66-1.73$ \\
\hline$\geq 4500$ & 22 & 1.38 & $0.89-2.12$ & 6 & 1.98 & $0.87-4.51$ \\
\hline Not known & 52 & 1.19 & $0.89-1.58$ & 8 & 1.01 & $0.49-2.07$ \\
\hline$p$ trend $^{d}$ & & 0.43 & & & 0.09 & \\
\hline \multicolumn{7}{|c|}{$p$ interaction $($ trend $)=0.06$} \\
\hline \multicolumn{7}{|c|}{ Gestation (weeks) } \\
\hline $26-31$ & 19 & 1.31 & $0.82-2.08$ & 3 & 0.97 & $0.31-3.06$ \\
\hline $32-36$ & 123 & 1.05 & $0.85-1.29$ & 23 & 0.95 & $0.60-1.52$ \\
\hline $37-39$ & 377 & 0.93 & $0.82-1.06$ & 81 & 0.91 & $0.68-1.21$ \\
\hline $40-41$ & 543 & 1.00 & & 115 & 1.00 & \\
\hline $42-49$ & 199 & 0.96 & $0.81-1.15$ & 38 & 0.84 & $0.57-1.24$ \\
\hline Not known & 169 & 1.02 & $0.85-1.22$ & 25 & 0.76 & $0.48-1.20$ \\
\hline$p$ trend $^{d}$ & & 0.06 & & & 0.55 & \\
\hline \multicolumn{7}{|c|}{$p$ interaction $($ trend $)=0.82$} \\
\hline
\end{tabular}

$H R$ hazard ratio, $\mathrm{Cl}$ confidence interval

${ }^{a}$ Oestrogen-receptor status of breast cancer

${ }^{b}$ Adjusted for: attained age (Cox regression time scale); time since recruitment to cohort (0, 1-2, 3+ years); birth cohort (1908-1939, 1940-1949, 1950-1959, 1960-1969, 1970-1996); benign breast disease (yes, no); family history of breast cancer in first-degree relatives (yes, no); socio-economic score (ACORN score as trend, missing); own birthweight (trend, missing); age at menarche (trend, missing); parity (trend); age at first pregnancy (trend); cumulative duration of breast feeding (none, duration trend when reported); current oral contraceptive use before menopause (yes, no); height at age 20 (trend, missing); alcohol consumption (never regular, trend current drinker 1 to $<60 \mathrm{~g} /$ day, current drinker $60+\mathrm{g} /$ day, past drinker, drinker with unknown details); age started smoking (never, $<17,17-19,20+$, missing); physical activity (log(metabolic equivalent) trend, missing); pre-menopausal body mass index at age 20 years (trend, missing); menopausal status (pre- or post-menopausal), and for those post-menopausal, post-menopausal body mass index (trend, missing), menopausal hormone therapy use (never used, ex-user, current oestrogen-only user, current oestrogen plus progestogen user, current user of other types, missing), and age at menopause (trend, missing)

${ }^{c} p<0.05$

${ }^{d}$ Excluding not known category

analysed only deliveries at $\geq 26$ weeks. Our analyses excluded births of twins, and in sensitivity analyses were not materially altered by exclusion of pre-eclamptic births, but we cannot exclude the possibility that other indications for early delivery were responsible for the raised risk after short gestation births.

The effect of gestation appeared to be greater for pre-menopausal than for post-menopausal breast cancer. No previous study has published analyses by menopausal status, but in several studies all, or almost all, cases were incident at ages under 50 years [18-20,33,34], or separate analyses were conducted for ages $<40$ years [17, 22], and therefore presumably largely pre-menopausal. Two studies found raised risks for short gestations in the presumed largely pre-menopausal group $[17,18]$, but several did not $[19,20,22,34]$. In one investigation, oestradiol levels in early pregnancy have been found to be associated with a raised risk of subsequent breast cancer at young ages [49], but in another they were not [50], and in general risks in such studies have been inconsistent and unreplicated $[49,50]$.

In our data, the effect of short gestation pregnancies was somewhat greater, but not significantly so, in the first 15 years after delivery. A potential reason is the higher oestrogen levels in pre-term than longer pregnancies [51, 52], which might then promote the growth of already transformed cells in the years soon after. The only previous analyses dividing at 15 years after delivery found no effect of short gestation before or after 15 years [21], or an effect peaking at 10-14 years [22].

Fewer previous studies have analysed the risk of breast cancer in relation to birthweight of the offspring than have analysed gestation. We found the risk was raised significantly after a high birthweight first-born and to a lesser 
Table 4 Invasive breast cancer risk by birthweight and gestation of firstborn singleton offspring by duration post-delivery

\begin{tabular}{|c|c|c|c|c|c|c|}
\hline & \multicolumn{6}{|c|}{ Time since first delivery } \\
\hline & \multicolumn{3}{|l|}{$<15$ years } & \multicolumn{3}{|l|}{$\geq 15$ years } \\
\hline & No. of cases & $H R^{a}$ & $95 \% \mathrm{Cl}$ & No. of cases & $H R^{a}$ & $95 \% \mathrm{Cl}$ \\
\hline \multicolumn{7}{|l|}{ Birthweight (g) } \\
\hline$<2000$ & 2 & 0.87 & $0.21-3.54$ & 16 & 1.27 & $0.77-2.09$ \\
\hline $2000-2499$ & 6 & 0.80 & $0.35-1.83$ & 61 & 1.06 & $0.82-1.38$ \\
\hline 2500-2999 & 22 & 0.78 & $0.49-1.26$ & 271 & 1.16 & $1.00-1.34^{\mathrm{b}}$ \\
\hline $3000-3499$ & 79 & 1.00 & & 597 & 1.00 & \\
\hline 3500-3999 & 62 & 0.95 & $0.68-1.32$ & 439 & 1.02 & $0.90-1.15$ \\
\hline $4000-4499$ & 18 & 0.94 & $0.56-1.58$ & 103 & 1.01 & $0.82-1.25$ \\
\hline$\geq 4500$ & 5 & 1.37 & $0.55-3.39$ & 25 & 1.56 & $1.04-2.33^{b}$ \\
\hline Not known & 8 & 1.48 & $0.72-3.07$ & 53 & 1.11 & $0.83-1.47$ \\
\hline$p$ trend $^{c}$ & & 0.42 & & & 0.53 & \\
\hline \multicolumn{7}{|c|}{$p$ interaction $($ trend $)=0.32$} \\
\hline \multicolumn{7}{|c|}{ Gestation (weeks) } \\
\hline $26-31$ & 4 & 1.93 & $0.71-5.27$ & 18 & 1.21 & $0.75-1.94$ \\
\hline $32-36$ & 17 & 1.30 & $0.78-2.19$ & 133 & 1.09 & $0.90-1.32$ \\
\hline $37-39$ & 46 & 0.73 & $0.51-1.04$ & 425 & 1.13 & $1.00-1.28$ \\
\hline $40-41$ & 94 & 1.00 & & 587 & 1.00 & \\
\hline$\geq 42$ & 33 & 0.95 & $0.64-1.42$ & 212 & 1.03 & $0.88-1.20$ \\
\hline Not known & 8 & 0.84 & $0.41-1.73$ & 190 & 1.06 & $0.90-1.25$ \\
\hline$p$ trend $^{c}$ & & 0.32 & & & 0.09 & \\
\hline$p$ interaction (t & & & & & & \\
\hline
\end{tabular}

$H R$ hazard ratio, $\mathrm{Cl}$ confidence interval

adjusted for: attained age (Cox regression time scale); time since recruitment to cohort (0, 1-2, 3+ years); birth cohort (1908-1939, 1940-1949, 1950-1959, 1960-1969, 1970-1996); benign breast disease (yes, no); family history of breast cancer in first-degree relatives (yes, no); socio-economic score (ACORN score as trend, missing); own birthweight (trend, missing); age at menarche (trend, missing); parity (trend); age at first pregnancy (trend); cumulative duration of breast feeding (none, duration trend when reported); current oral contraceptive use before menopause (yes, no); height at age 20 (trend, missing); alcohol consumption (never regular, trend current drinker 1 to $<60 \mathrm{~g} /$ day, current drinker 60+ g/day, past drinker, drinker with unknown details); age started smoking (never, $<17,17-19,20+$, missing); physical activity (log(metabolic equivalent) trend, missing); pre-menopausal body mass index at age 20 years (trend, missing); menopausal status (pre- or post-menopausal), and for those post-menopausal, post-menopausal body mass index (trend, missing), menopausal hormone therapy use (never used, ex-user, current oestrogen-only user, current oestrogen plus progestogen user, current user of other types, missing), and age at menopause (trend, missing) ${ }^{\mathrm{b}} p<0.05$

${ }^{\mathrm{c} E x c l u d i n g}$ not known category

extent also after the lowest birthweights. Most other studies have also found the risk raised after a high birthweight first-born [7, 19-21, 23], although one found the opposite [18] and some reported no relation based on smaller numbers $[16,53]$. Published risks have not been raised, however, for women with low birthweight offspring.

Women giving birth to heavier offspring tend to have higher oestrogen and free oestrogen levels [8, 9, 12-14] and insulin-like growth factor 1 (IGF1) levels [10] in pregnancy, giving a plausible mechanism for an association of high birthweight of offspring with maternal breast cancer risk.

The association of gestation with breast cancer risk was similar for ER-positive tumours to that for breast cancer overall (although not significantly, based on smaller numbers), but an association was not seen for ER-negative cancer. There do not appear to be any previous analyses by hormone receptor status with which to compare this. For high birthweight, the effect was greater, but not significantly so, for ER-negative tumours, in accord with the only previous, also not significant, analysis [23]. The effects of birthweight and gestation appeared not to be present, albeit based on smaller numbers, for in-situ rather than invasive tumours. To our knowledge there have been no previous analyses of risks of in-situ tumours.

While hormonal and histological explanations for the relation of gestation and birthweight to breast cancer risk seem the most obvious, it is also possible that maternal genetic susceptibility loci affecting offspring birthweight [54] or gestation [55] may affect breast cancer risk.

Our analyses of risk in relation to gestation and birthweight of most recent birth found no clear relations. This accords with the general tendency for first birth (e.g. age at this birth) to have a much greater impact on breast 
Table 5 Invasive breast cancer risk by birthweight and gestation of most-recent singleton birth ${ }^{a}$ by menopausal status ${ }^{b}$

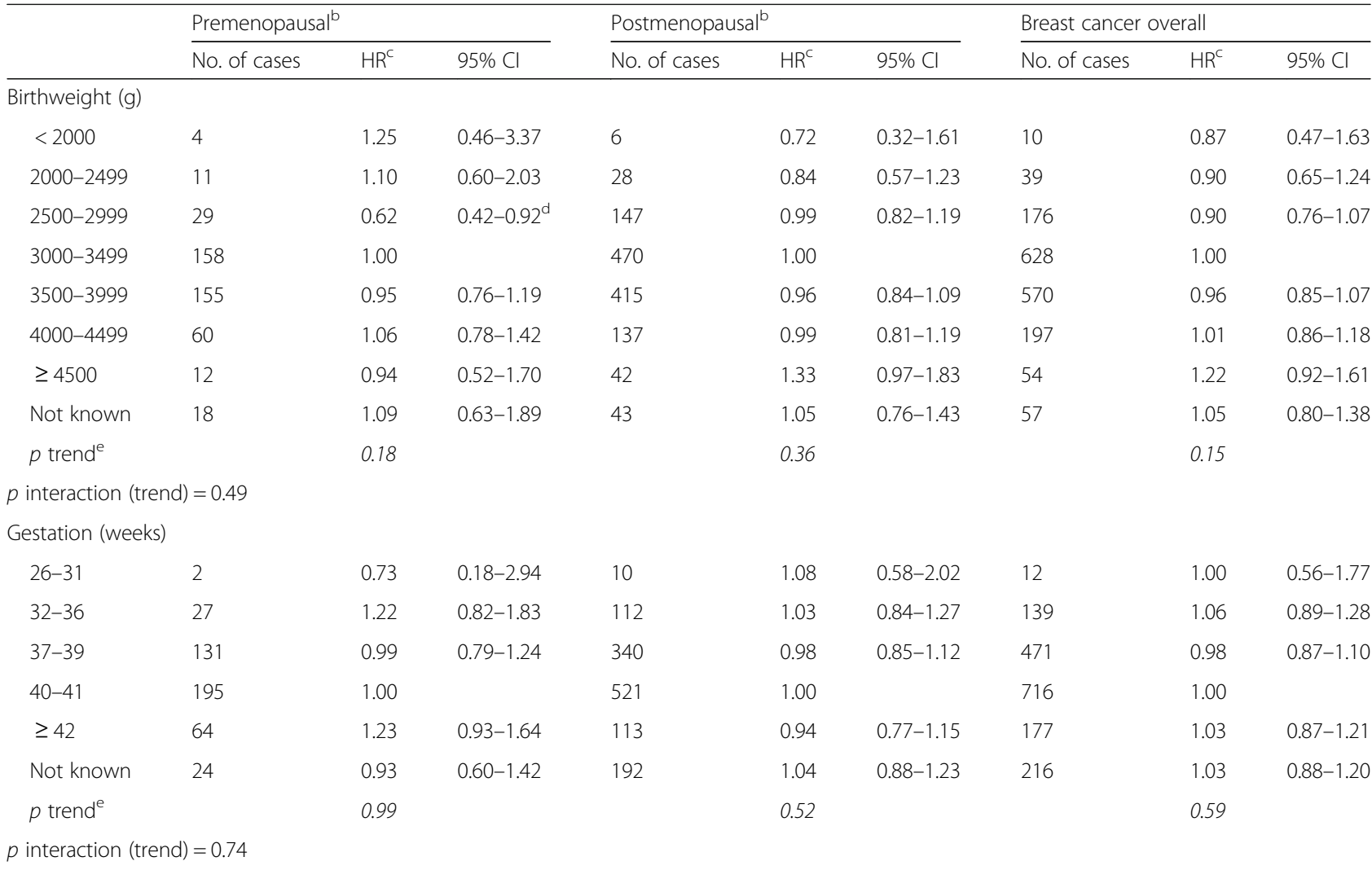

$H R$ hazard ratio, $\mathrm{Cl}$ confidence interval

${ }^{a}$ Women are censored (removed from further analytic follow-up) upon reaching a twin pregnancy

${ }^{b}$ Menopausal status at breast cancer incidence

'Adjusted for: attained age (Cox regression time scale); time since recruitment to cohort (0, 1-2, 3+ years); birth cohort (1908-1939, 1940-1949, 1950-1959, 1960-1969, 1970-1996); benign breast disease (yes, no); family history of breast cancer in first-degree relatives (yes, no); socio-economic score (ACORN score as trend, missing); own birthweight (trend, missing); age at menarche (trend, missing); parity (trend); age at first pregnancy (trend); cumulative duration of breast feeding (none, duration trend when reported); current oral contraceptive use before menopause (yes, no); height at age 20 (trend, missing); alcohol consumption (never regular, trend current drinker 1 to $<60 \mathrm{~g} /$ day, current drinker $60+\mathrm{g} /$ day, past drinker, drinker with unknown details); age started smoking (never, $<17,17-19,20+$, missing); physical activity (log(metabolic equivalent) trend, missing); pre-menopausal body mass index at age 20 years (trend, missing); menopausal status (pre- or post-menopausal), and for those post-menopausal, post-menopausal body mass index (trend, missing), menopausal hormone therapy use (never used, ex-user, current oestrogen-only user, current oestrogen plus progestogen user, current user of other types, missing), and age at menopause (trend, missing) ${ }^{d} p<0.05$

excluding not known category

cancer risk than do subsequent births. The only previous analysis to provide data comparing breast cancer risk in relation to first birth and last birth found no significant effect of birthweight or gestation at either [20].

The previous literature on breast cancer risks in relation to gestation and birthweight of the offspring has, with two exceptions based on small numbers [7,53], been based on record linkage. This has the great strengths of using recorded data on pregnancy variables, and in certain instances of very large numbers of cases [15, 20, 21, 23, 24], but also certain disadvantages which make the data not entirely comparable with ours. First, these studies had little $[19,33]$ or no $[15,17,18,20-24,34]$ ability to adjust their risk estimates for potential non-reproductive confounders such as maternal height, birthweight, alcohol, and smoking, nor for an important reproductive-related confounder, breast feeding [56]. Secondly, in several instances [16, 17,
$21,53]$, the birth analysed was the first within the period of recorded data covered in the study, rather than the first in the woman's reproductive history. Thirdly, while the Scandinavian studies [15-17, 19, 22-24] were based on national follow-up, the large record-linkage studies from the US included only women whose birth and subsequent cancer had both occurred in the same state [18, 20,21], with a potential for bias.

The quality of birth certificate data on birthweight tends to be high $[57,58]$, but data quality is also high in recall by mothers [59]. Overall, our analyses based on a recruited epidemiological cohort, and those previously based on record linkage, have different strengths and weaknesses; hence, when they find similar results, this strengthens the case that these are real effects, not artefacts. For the effects of short gestation and high birthweight, our results are similar to those from the 
preponderance of record linkage studies and, with one exception for gestation [19] and one for birthweight [16], to all those from record linkage cohort studies.

\section{Conclusions}

Our data add to evidence that a short gestation compared with a longer gestation first pregnancy results in increased breast cancer risk, and suggest that this increase occurs in pre-menopausal but not post-menopausal women. A potential mechanism is that short gestation pregnancies may result in hormonal stimulation and breast proliferation early in pregnancy, without the opportunity for differentiation occurring later in pregnancy. On birthweight, we found a raised risk for mothers of heavier first-borns, in accord with most previous studies, and potentially acting via the association of birthweight with oestrogen and IGF1 levels.

\section{Additional file}

Additional file 1: Table S1. In-situ breast cancer risk by birthweight and gestation of first-born singleton offspring by menopausal status. Table S2. Invasive breast cancer risk by birthweight and gestation of first-born by age at first delivery. Table S3. Relative risks of invasive breast cancer in relation to birthweight and gestation of first-born singleton offspring by menopausal status at breast cancer incidence; analyses unadjusted for confounders other than age. Table S4. Relative risks of invasive breast cancer in relation to birthweight and gestation of firstborn singleton offspring by oestrogen receptor status of breast cancer; analyses unadjusted for confounders other than age. Table S5. Relative risks of invasive breast cancer in relation to birthweight and gestation of first-born singleton offspring by duration since delivery; analyses unadjusted for confounders other than age. Table S6. Relative risks of invasive breast cancer in relation to birthweight and gestation of most recent singleton birth by menopausal status at breast cancer incidence; analyses unadjusted for confounders other than age. (DOCX $53 \mathrm{~kb}$ )

\section{Abbreviations}

$\mathrm{Cl}$ : Confidence interval; ER: Oestrogen receptor; HR: Hazard ratio; IGF1: Insulin-like growth factor 1; NHSCR: National Health Service Central Register

\section{Acknowledgements}

We thank Breast Cancer Now and The Institute of Cancer Research for support of the Generations Study, as well as the study participants, study staff, and the doctors, nurses and other health care staff and data providers who have contributed to the study.

\section{Funding}

This work was funded by Breast Cancer Now and The Institute of Cancer Research. We acknowledge National Health Service (NHS) funding to the Royal Marsden NHS Foundation Trust and The Institute of Cancer Research National Institute for Health Research (NIHR) Biomedical Research Centre. The funders did not participate in the design of the study, the analysis or interpretation of data, or in the writing or approval of the manuscript.

\section{Availability of data and materials}

The datasets generated during and/or analysed during the present study are not publicly available, for reasons of confidentiality, but anonymised versions may be available from the corresponding author on reasonable request.

\section{Authors' contributions}

AJS designed the study, obtained funding for the Generations Study, and drafted the manuscript. AJS, MEJ, and MJS set up and collected data in the
Generations Study. MEJ, MJS, and LBW collected and prepared data for the analysis. MEJ conducted the analyses. All authors contributed to data interpretation and preparation of the final manuscript. All authors read and approved the final manuscript.

\section{Ethics approval and consent to participate}

The study was approved by the South Thames Multi-centre Research Ethics Committee (reference MREC 03/01/014), and participants provided informed consent.

\section{Consent for publication}

Not applicable.

\section{Competing interests}

The authors declare that they have no competing interests.

\section{Publisher's Note}

Springer Nature remains neutral with regard to jurisdictional claims in published maps and institutional affiliations.

Received: 11 June 2018 Accepted: 1 August 2018

Published online: 05 October 2018

References

1. MacMahon B, Cole P, Lin TM, Lowe CR, Mirra AP, Ravnihar B, Salber EJ, Valaoras VG, Yuasa S. Age at first birth and breast cancer risk. Bull World Health Organ. 1970;43(2):209-21.

2. Lane-Claypon JE. A further report on cancer of the breast, with special reference to its associated antecedent conditions. In: Reports on public health and medical subjects No 32. His Majesty's Stationery Office. London: Ministry of Health; 1926.

3. Trichopoulos D. Hypothesis: does breast cancer originate in utero? Lancet. 1990;335(8695):939-40.

4. Hill M, Parizek A, Kancheva R, Duskova M, Velikova M, Kriz L, Klimkova M, Paskova A, Zizka Z, Matucha P, et al. Steroid metabolome in plasma from the umbilical artery, umbilical vein, maternal cubital vein and in amniotic fluid in normal and preterm labor. J Steroid Biochem Mol Biol. 2010;121(3-5):594-610.

5. Clapp JF, Schmidt S, Paranjape A, Lopez B. Maternal insulin-like growth factor-I levels (IGF-I) reflect placental mass and neonatal fat mass. Am J Obstet Gynecol. 2004;190(3):730-6.

6. Russo J, Russo IH. Development of the human breast. Maturitas. 2004; 49(1):2-15.

7. Bukowski R, Chlebowski RT, Thune I, Furberg AS, Hankins GD, Malone FD, D'Alton ME. Birth weight, breast cancer and the potential mediating hormonal environment. PLoS One. 2012;7(7):e40199.

8. Kaijser M, Granath F, Jacobsen G, Cnattingius S, Ekbom A. Maternal pregnancy estriol levels in relation to anamnestic and fetal anthropometric data. Epidemiology. 2000;11(3):315-9.

9. Nagata C, Iwasa S, Shiraki M, Shimizu H. Estrogen and alpha-fetoprotein levels in maternal and umbilical cord blood samples in relation to birth weight. Cancer Epidemiol Biomark Prev. 2006;15(8):1469-72.

10. Boyne MS, Thame M, Bennett Fl, Osmond C, Miell JP, Forrester TE. The relationship among circulating insulin-like growth factor (IGF)-I, IGF-binding proteins-1 and -2, and birth anthropometry: a prospective study. J Clin Endocrinol Metab. 2003;88(4):1687-91.

11. Holmes R, Montemagno $R$, Jones J, Preece M, Rodeck C, Soothill P. Fetal and maternal plasma insulin-like growth factors and binding proteins in pregnancies with appropriate or retarded fetal growth. Early Hum Dev. 1997:49(1):7-17

12. Troisi R, Potischman N, Roberts J, Siiteri P, Daftary A, Sims C, Hoover RN. Associations of maternal and umbilical cord hormone concentrations with maternal, gestational and neonatal factors (United States). Cancer Causes Control. 2003;14(4):347-55.

13. Peck JD, Hulka BS, Savitz DA, Baird D, Poole C, Richardson BE. Accuracy of fetal growth indicators as surrogate measures of steroid hormone levels during pregnancy. Am J Epidemiol. 2003;157(3):258-66.

14. Mucci LA, Lagiou P, Tamimi RM, Hsieh CC, Adami HO, Trichopoulos D. Pregnancy estriol, estradiol, progesterone and prolactin in relation to birth weight and other birth size variables (United States). Cancer Causes Control. 2003;14(4):311-8. 
15. Vatten LJ, Romundstad PR, Trichopoulos D, Skjaerven R. Pregnancy related protection against breast cancer depends on length of gestation. $\mathrm{Br}$ J Cancer. 2002:87(3):289-90.

16. Mogren I, Stenlund $H$, Hogberg U. Long-term impact of reproductive factors on the risk of cervical, endometrial, ovarian and breast cancer. Acta Oncol. 2001;40(7):849-54.

17. Melbye M, Wohlfahrt J, Andersen AM, Westergaard T, Andersen PK. Preterm delivery and risk of breast cancer. Br J Cancer. 1999;80(3-4):609-13.

18. Innes KE, Byers TE. First pregnancy characteristics and subsequent breast cancer risk among young women. Int J Cancer. 2004;112(2):306-11.

19. Cnattingius S, Torrang A, Ekbom A, Granath F, Petersson G, Lambe M. Pregnancy characteristics and maternal risk of breast cancer. JAMA. 2005; 294(19):2474-80

20. Nechuta S, Paneth N, Pathak DR, Gardiner J, Copeland G, Velie EM. A population-based case-control study of fetal growth, gestational age, and maternal breast cancer. Am J Epidemiol. 2010;172(8):962-70.

21. Troisi R, Doody DR, Mueller BA. A linked-registry study of gestational factors and subsequent breast cancer risk in the mother. Cancer Epidemiol Biomark Prev. 2013;22(5):835-47.

22. Hsieh CC, Wuu J, Lambe M, Trichopoulos D, Adami HO, Ekbom A. Delivery of premature newborns and maternal breast-cancer risk. Lancet. 1999; 353(9160):1239.

23. Wohlfahrt J, Melbye M. Maternal risk of breast cancer and birth characteristics of offspring by time since birth. Epidemiology. 1999;10(4):441-4.

24. Olsen J, Storm H. Pregnancy experience in women who later developed oestrogen-related cancers (Denmark). Cancer Causes Control. 1998;9(6):653-7.

25. Savitz DA, Dole N, Herring AH, Kaczor D, Murphy J, Siega-Riz AM, Thorp JM Jr, MacDonald TL. Should spontaneous and medically indicated preterm births be separated for studying aetiology? Paediatr Perinat Epidemiol. 2005; 19(2):97-105.

26. Goldenberg RL, Culhane JF, lams JD, Romero R. Epidemiology and causes of preterm birth. Lancet. 2008;371(9606):75-84.

27. Dougherty $C R$, Jones $A D$. The determinants of birth weight. Am J Obstet Gynecol. 1982;144(2):190-200.

28. Petridou E, Panagiotopoulou K, Katsouyanni K, Spanos E, Trichopoulos D. Tobacco smoking, pregnancy estrogens, and birth weight. Epidemiology. 1990;1(3):247-50.

29. Han Z, Lutsiv O, Mulla S, McDonald SD, Knowledge Synthesis Group. Maternal height and the risk of preterm birth and low birth weight: a systematic review and meta-analyses. J Obstet Gynaecol Can. 2012;34(8): 721-46.

30. Mattsson K, Rylander L. Influence of maternal and paternal birthweight on offspring birthweight - a population-based intergenerational study. Paediatr Perinat Epidemiol. 2013;27(2):138-44.

31. Patra J, Bakker R, Irving H, Jaddoe W, Malini S, Rehm J. Dose-response relationship between alcohol consumption before and during pregnancy and the risks of low birthweight, preterm birth and small for gestational age (SGA)—a systematic review and meta-analyses. BJOG. 2011;118(12):1411-21.

32. Swerdlow AJ, Jones ME, Schoemaker MJ, Hemming J, Thomas D, Williamson J, Ashworth A. The Breakthrough Generations Study: design of a long-term UK cohort study to investigate breast cancer aetiology. Br J Cancer. 2011; 105(7):911-7.

33. Ardalan A, Bungum T. Gestational age and the risk of maternal breast cancer: a population-based case-control study. Breast J. 2016;22(6):657-61.

34. Polednak AP, Janerich DT. Characteristics of first pregnancy in relation to early breast cancer. A case-control study. J Reprod Med. 1983;28(5):314-8.

35. Ji J, Forsti A, Sundquist J, Hemminki K. Risks of breast, endometrial, and ovarian cancers after twin births. Endocr Relat Cancer. 2007;14(3):703-11.

36. Lambe M, Hsieh C, Trichopoulos D, Ekbom A, Pavia M, Adami HO. Transient increase in the risk of breast cancer after giving birth. N Engl J Med. 1994; 331(1):5-9.

37. Cox DR. Regression models and life-tables. J R Stat Soc Ser B. 1972;34: $187-220$.

38. StataCorp. Stata statistical software: release 14. College Station: StataCorpLP; 2015.

39. Buse A. The likelihood ratio, Wald, and Lagrange multiplier tests-an expository note. Am Stat. 1982;36(3):153-7.

40. Lunn M, McNeil D. Applying cox regression to competing risks. Biometrics. 1995;51(2):524-32.

41. Pacheco NL, Andersen AM, Kamper-Jorgensen M. Preeclampsia and breast cancer: the influence of birth characteristics. Breast. 2015;24(5):613-7.
42. Larsson SC, Mantzoros CS, Wolk A. Diabetes mellitus and risk of breast cancer: a meta-analysis. Int J Cancer. 2007;121(4):856-62.

43. Dankner R, Boffetta P, Balicer RD, Boker LK, Sadeh M, Berlin A, Olmer L, Goldfracht M, Freedman LS. Time-dependent risk of cancer after a diabetes diagnosis in a cohort of 2.3 million adults. Am J Epidemiol. 2016;183(12):1098-106.

44. Hunt KJ, Marlow NM, Gebregziabher M, Ellerbe CN, Mauldin J, Mayorga ME, Korte JE. Impact of maternal diabetes on birthweight is greater in non-Hispanic blacks than in non-Hispanic whites. Diabetologia. 2012;55(4):971-80.

45. Russo J, Russo $\mathrm{H}$. Susceptibility of the mammary gland to carcinogenesis. II. Pregnancy interruption as a risk factor in tumor incidence. Am J Pathol. 1980;100(2):497-512.

46. Russo J, Tay LK, Russo IH. Differentiation of the mammary gland and susceptibility to carcinogenesis. Breast Cancer Res Treat. 1982;2(1):5-73.

47. Ferguson DJ, Anderson TJ. A morphological study of the changes which occur during pregnancy in the human breast. Virchows Arch A Pathol Anat Histopathol. 1983;401(2):163-75.

48. Melbye M, Wohlfahrt J, Olsen JH, Frisch M, Westergaard T, Helweg-Larsen K, Andersen PK. Induced abortion and the risk of breast cancer. N Engl J Med. 1997;336(2):81-5.

49. Lukanova A, Surcel HM, Lundin E, Kaasila M, Lakso HA, Schock H, Husing A, Kaaks R, Koskela P, Grankvist K, et al. Circulating estrogens and progesterone during primiparous pregnancies and risk of maternal breast cancer. Int J Cancer. 2012;130(4):910-20.

50. Fortner RT, Tolockiene E, Schock H, Oda H, Lakso HA, Hallmans G, Kaaks R, Toniolo P, Zeleniuch-Jacquotte A, Grankvist K, et al. Early pregnancy sex steroids during primiparous pregnancies and maternal breast cancer: a nested case-control study in the northern Sweden maternity cohort. Breast Cancer Res. 2017;19(1):82.

51. Wuu J, Hellerstein S, Lipworth L, Wide L, Xu B, Yu GP, Kuper H, Lagiou P, Hankinson SE, Ekbom A, et al. Correlates of pregnancy oestrogen, progesterone and sex hormone-binding globulin in the USA and China. Eur J Cancer Prev. 2002;11(3):283-93.

52. Mazor M, Hershkovitz R, Chaim W, Levy J, Sharony $Y$, Leiberman JR, Glezerman M. Human preterm birth is associated with systemic and local changes in progesterone/17 beta-estradiol ratios. Am J Obstet Gynecol. 1994;171(1):231-6.

53. Cohn BA, Cirillo PM, Christianson RE, van den Berg BJ, Siiteri PK. Placental characteristics and reduced risk of maternal breast cancer. J Natl Cancer Inst. 2001;93(15):1133-40.

54. Beaumont RN, Warrington NM, Cavadino A, Tyrrell J, Nodzenski M, Horikoshi M, Geller F, Myhre R, Richmond RC, Paternoster L, et al. Genome-wide association study of offspring birth weight in 86577 women identifies five novel loci and highlights maternal genetic effects that are independent of fetal genetics. Hum Mol Genet. 2018;27(4):742-56.

55. Zhang G, Feenstra B, Bacelis J, Liu X, Muglia LM, Juodakis J, Miller DE, Litterman $N$, Jiang PP, Russell $L$, et al. Genetic associations with gestational duration and spontaneous preterm birth. N Engl J Med. 2017;377(12):1156-67.

56. Merewood A, Brooks D, Bauchner H, MacAuley L, Mehta SD. Maternal birthplace and breastfeeding initiation among term and preterm infants: a statewide assessment for Massachusetts. Pediatrics. 2006;118(4):e1048-54.

57. DiGiuseppe DL, Aron DC, Ranbom L, Harper DL, Rosenthal GE. Reliability of birth certificate data: a multi-hospital comparison to medical records information. Matern Child Health J. 2002;6(3):169-79.

58. David RJ. The quality and completeness of birthweight and gestational age data in computerized birth files. Am J Public Health. 1980;70(9):964-73.

59. Tomeo CA, Rich-Edwards JW, Michels KB, Berkey CS, Hunter DJ, Frazier AL, Willett WC, Buka SL. Reproducibility and validity of maternal recall of pregnancy-related events. Epidemiology. 1999;10(6):774-7. 